\title{
PEMBUATAN MEDIA PEMBELAJARAN BERBASIS VIDEO MATA KULIAH PENGATURAN MOTOR (STUDI PADA PROGRAM STUDI PENDIDIKAN TEKNIK ELEKTRO, FAKULTAS TEKNIK, UNIVERSITAS NEGERI JAKARTA)
}

${ }^{1}$ Diah Yuni Purwitaingsih, ${ }^{2}$ Imam Arif Raharjo, dan ${ }^{3}$ Massus Subekti.

1,2,3PendidikanTeknik Elektro, Fakultas Teknik, Universitas Negeri Jakarta ${ }^{1}$ Email : diah_yuni_213@yahoo.com

\begin{abstract}
.
This research aimed to create and utilize video-based learning media on motor control course and also to determine whether the video-based learning media on motor control course is effective or not. The making of the video-based learning media using several stages, namely, literature study, analysis needs, product planning, product making, instrument making feasibility and feasibility studies that are conducted by the experts, media specialists and students in order to determine the feasibility of the media created. Furthermore, to test the effectiveness of video-based learning media on motor control course, students are given the posttest questions that the validity and reliability have previously been tested by using an experimental model. The results of the feasibility test got a score > 80\%, subject experts got a score of $94.23 \%$, media experts $91,66 \%$, and students $86.13 \%$. The results of the feasibility test obtained, video-based learning media on motor control course is said to be very good and fit for use as a media of learning. The average value of students post test using a video-based learning media is 83, while students who do not use a video-based learning media have an average of 80.56. These data showed that value of post test results of motor control course that uses video-based learning media is higher than value of post test results that does not use a video-based learning media. The difference in post test results show that a video-based learning media on motor control course is an effective media of learning.
\end{abstract}

Keywords: Making, video-based learning media on motor control, study outcomes post test

\begin{abstract}
Abstrak
Penelitian ini bertujuan untuk membuat dan memanfaatkan media pembelajaran berbasis video mata kuliah pengaturan motor untuk mengetahui apakah media pembelajaran berbasis video ini efektif atau tidak. Pembuatan media pembelajaran berbasis video ini menggunakan beberapa tahapan yaitu, studi literatur, analisis kebutuhan, perencanaan produk, pembuatan produk, pembuatan instrumen uji kelayakan dan uji kelayakan yang dilakukan oleh ahli materi, ahli media dan mahasiswa guna mengetahui kelayakan media yang dibuat. Selanjutnya untuk menguji keefektifan dari media pembelajaran berbasis video mata kuliah pengaturan motor, mahasiswa diberikan soal post test yang sebelumnya sudah di uji validitas dan reabilitasnya dengan menggunakan model eksperimen.

Hasil uji kelayakan mendapatkan skor $>80 \%$ yaitu ahli materi mendapat skor sebesar $94,23 \%$, ahli media 91,66\%, dan mahasiswa 86,13\%. Dari hasil tersebut, media pembelajaran berbasis video mata kuliah pengaturan motor sangat baik dan layak digunakan sebagai media pembelajaran. Rata-rata nilai post test mahasiswa yang menggunakan media pembelajaran berbasis video sebesar 83, sedangkan mahasiswa yang tidak menggunakan media pembelajaran berbasis video memiliki rata-rata sebesar 80,56 . Dari data tersebut menunjukkan bahwa hasil nilai post test yang menggunakan media pembelajaran berbasis video lebih tinggi dibandingkan dengan hasil nilai post test yang tidak menggunakan media pembelajaran berbasis video. Dari perbedaan hasil post test tersebut menunjukan bahwa media pembelajaran berbasis video mata kuliah pengaturan motor efektif digunakan sebagai media pembelajaran.
\end{abstract}

Kata Kunci: Pembuatan, media pembelajaran berbasis video pengaturan motor,hasil belajar post test

\section{PENDAHULUAN}

Ilmu pengetahuan teknologi telah mengalami perkembangan yang sangat pesat, hal ini berdampak signifikan pada pola pikir masyarakat. Dalam bidang pendidikan, perubahan-perubahan banyak memberikan pengalaman baru sekaligus merupakan tantangan bagi para pendidik untuk memanfaatkan perubahan tersebut menjadi salah satu modal penting penyelenggaraan kegiatan pembelajaran yang lebih efektif dan efisien. Semua usaha pengumpulan, pengelolaan, penyimpanan dan penyajian informasi senantiasa menggunakan peran media sehingga menjadi kebutuhan dalam kegiatan pembelajaran. Oleh sebab itu, media pembelajaran dapat menjadi modal penting 
dalam penyelenggaraan kegiatan pembelajaran yang efektif dan efisien.

Peran media pembelajaran semakin penting dan menjadi kebutuhan guna memberikan alternatif sumber belajar bagi mahasiswa yang menurut konsep pendidikan Student Centered Learning (Mahasiswa Pusat Pembelajaran), dituntut untuk aktif belajar dengan pengalaman langsung dengan menggunakan berbagai sumber belajar, karena dosen kini tidak lagi menjadi pusat kegiatan belajar mengajar. Upaya untuk menciptakan keterampilan adalah dengan memperkaya pelatihan praktik. Dalam hal ini terkadang mahasiswa masih belum memahami apa yang dijelaskan oleh dosen.

Penggunaan media yang tepat dapat membantu proses belajar mahasiswa agar mahasiswa lebih memahami untuk tercapainya tujuan belajar. Untuk itu penyampaian materi dan praktik dengan ditunjang bimbingan yang praktis, harus merujuk kepada perkembangan pemanfaatan teknologi informasi. Dalam hal ini media audio visual dalam bentuk video sangat tepat sebagai sumber belajar. Penggunaan video sebagai sumber pembelajaran sangatlah penting, seperti dikemukakan para ahli, dalam menyimpanan dan memproses informasi secara linear, rangsangan otak akan lebih mudah menerimanya dalam bentuk gambar, warnawarni, simbol, bunyi dan perasaan (Porter, dkk., 2000: 176).

Hal inilah yang menjadi landasan penulis membuat suatu penilitian skripsi tentang pembuatan media pembelajaran berbasis video mata kuliah pengaturan motor. Pemanfaatan video ini bertujuan untuk menambah keterampilan mahasiswa dalam melakukan praktik maupun pemahaman materi Mata Kuliah Pengaturan Motor agar dapat melihat keefaktifan produk terhadap hasil belajar mahasiswa.

\section{METODE}

\section{Tempat dan Waktu Penelitian}

Pembuatandan penelitian media pembelajaran berbasis video mata kuliah Pengaturan Motor iniberlangsungdi Laboratorium Pengaturan Motor, Jurusan
Teknik Elektro, Fakultas Teknik,UniversitasNegeriJakartapadabulanJanu arisampai

Junisemestergenaptahunajaran2015/2016.

Metode Penelitian

Pada penelitian ini digunakan metode penelitian pengembangan (development research).

Prosedur Penelitian

a. Studi Literatur

Studi literatur digunakan untuk mengetahui keadaan yang terjadi di lapangan.

b. Analisis Kebutuhan Mengetahui pendapat mahasiswa dan dosen mengenai pembuatan media pembelajaran berbasis video.

c. Perancangan Produk

Tahap perencanaan meliputi pematangan ide sekenario, pembuatan story board dan penulisan naskah sekenario.

d. Pembuatan Produk

Pembuatan media pembelajaran berbasis video hingga tahap penyelesaian akhir.

e. Pembuatan Instrumen Uji Kelayakan Penulis menggunakan instrumen yang bersumber dari buku Media Pembelajaran pengarang Cecep Kustandi dan Bambang Sutjipto.

f. Validasi Ahli Media dan Ahli Materi Uji kelayakan produk serta memperoleh informasi berupa perbaikan, kritik dan saran untuk evaluasi dan revisi. Hasil uji kelayakan dikatakan layak jika mendapat skor $>80 \%$.

g. Revisi Produk

Revisi dilakukan berdasarkan hasil dari uji coba produk yang pertama agar kekurangan dan kelemahan dapat diketahui sebelum uji coba pemakaian dilakukan.

h. Pembuatan Kisi-Kisi Instrumen Soal Pembuatan kisi-kisi soal yang dibuat berdasarkan indikator-indikator dari materi pelajaran.

i. Uji Validitas \& Reliabilitas Soal 
Untuk melihat apakah butir-butir soal yang dibuat dari kisi-kisi soal tersebut valid atau tidak dan reliabel.

j. Uji Coba Produk ke Mahasiswa

Uji coba produk berupa pengujian media pembelajaran berbasis video kepada mahasiswa. Pada tahap ini, dilakukan pengujian dengan metode eskperimen. Eksperimen dilakukan dengan membandingkan dua kelompok kelas yang diberikan perlakuan berbeda. Kelompok kelas yang pertama menggunakan media pembelajaran dan kelompok kelas yang kedua menggunakan media pembelajaran ceramah.

Tabel 1. Model Eksperimen

\begin{tabular}{ccc}
$\begin{array}{c}\text { Kelompok } \\
\text { acak }\end{array}$ & $\begin{array}{c}\text { Perlak } \\
\text { uan }\end{array}$ & $\begin{array}{c}\text { akhi } \\
\text { r }\end{array}$ \\
Eksperimen & X1 & Y \\
Kontrol & X2 & Y \\
\hline
\end{tabular}

Keterangan:

X1 : Perlakuan pembelajaran menggunakanmedia pembelajaran berbasis video.

X2 : Perlakuan pembelajaran tidak menggunakan media pembelajaranberbasis video (konvensional).

Y : Test Akhir

k. Revisi Produk

(Penyempurnaan Produk Akhir)yang diperoleh berdasarkan uji coba pada mahasiswa dan dosen ahli.

1. Produk Akhir

Pembuatan produk ini dilakukan apabila desain produk telah diperbaiki melalui beberapa uji coba yang telah dilakukan.

\section{Teknik Pengumpulan Data}

Datayangdigunakan

dalamskripsiinimerupakandatahasilujikelayaka n (validasi)oleh ahlimedia, ahli materidanmahasiswa.Dataini diperolehdenganmenggunakaninstrumen ujikelayakanberupabeberapa angketyangtelahdiisiolehpararespondensetelah mencermativideo tersebut. Selain itu, diuji coba dengan soal guna mengetahui keefektifan media pembelajaran berbasis video.

\section{Instrumen Penelitian}

1. Instrumen Uji Kelayakan

Instrumenuji kelayakan olehahlimedia dan ahli materi,untukmengukuraspek isi atau materi, pembelajaran dan aspek media.

Instrumenujikelayakanoleh mahasiswa, untuk mengetahuikelayakan media pembelajaran berbasis video mata kuliah pengaturan motor.

2. Kisi-Kisi Instrumen Soal

Soal dibuat sebanyak 40 soal dengan 5 alternatif jawaban yang memperhatikan ranah mengingat $(\mathrm{C} 1)$, memahami (C2), menerapkan (C3) dan menganalisis (C4) yang diuji dengan uji prasyarat instrumen.

3. Uji Prasyarat Instrumen

Serangkaian pengujian yang dilakukan terhadap soal-soal yang akan diujikan kepada mahasiswa adalah validitas, tingkat kesukaran, daya pembeda dan reliabilitas.

\section{Teknik Analisis Data}

Teknik Analisis data berupa data statistika deskriptif yang dilakukan dari skor rata-rata uji validasi oleh ahli materi, ahli media dan mahasiswa yang merupakan dasar penilaian kelayakan Selanjutnya untuk melihat keefektifan media pembelajaran berbasis video mata kuliah pengaturan motor, didapat dari hasil rata-rata uji coba dengan menggunakan soal post test untuk mengetahui apakah ada perbedaanhasil belajar yang menggunakan video dengan yang tidak menggunakan video.

\section{HASIL DAN PEMBAHASAN}

Nama produk yang dihasilkan adalah Video Pembelajaran Pengaturan motor. Media pembelajaran berbasis video ini berdasarkan salah satu kompetensi dasar mata kuliah pengaturan motor pada Buku Pedoman Akademik (BPA) Fakultas Teknik, untuk Prodi Pendidikan Teknik Elektro, yaitu mengenai starting motor-motor induksi dan pengaturan motor induksi 3 fasa.

\section{Kelayakan Produk}

1. Hasil Uji Kelayakan oleh Ahli Materi. Ahli materi adalah Drs. Purwanto Gendroyono, 
MT selaku Dosen Universitas Negeri Jakarta, Fakultas Teknik, Program Studi Pendidikan Teknik Elektro. Skor total yang diperoleh sebesar 49, sehingga diperoleh nilai sebesar $94,23 \%$.

2. Hasil Uji Kelayakan oleh Ahli Media. Ahli media adalah Drs. Robinson Situmorang, M.Pd selaku Dosen Universitas Negeri Jakarta, Fakultas Ilmu Pendidikan, Program Studi Teknologi Pendidikan. Skor total yang diperoleh sebesar 55, sehingga diperoleh nilai sebesar $91,66 \%$

3. Hasil Uji Kelayakan oleh Mahasiswa. Responden mahasiswa yang diberikan instrumen uji kelayakan berjumlah 30 orang, yang diambil dari kelas eksperimen. Ratarata total yang didapat yaitu sebesar $86,13 \%$.

\section{Efektifitas Produk}

Hasil Uji Instrumen Soal

1. Hasil Uji Validitas

Hasil validitas menyatakan

bahwa dari 40 soal yang dibuat

terdapat 10 soal yang tidak valid.

2. Hasil Tingkat Kesukaran

Hasil dari tingkat kesukaran

yaitu 29 soal mudah, 8 soal

sedang, dan 3 soal sukar.

3. Hasil Daya Pembeda

Hasil dari daya pembeda yaitu

14 soal dinyatakan jelek, Soal

yang dinyatakan cukup yaitu

terdapat 18 soal. Sedangkan

untuk soal yang baik yaitu 8 .

4. Hasil Reliabilitas

Hasil dari reliabilitas yaitu

sebesar 0,779. Hasil reliabilitas

tersebut kemudian dibandingkan

dengan nilai $r$ sesuai pada tabel

harga dari r product moment

yaitu $r=0,361$. Nilai $r_{\text {hitung }}>r_{\text {tabel }}$

atau 0,779>0,361. Maka, dapat

dikatakan soal ini reliabel.

\section{Hasil Nilai Post Test}

Posttest menggunakan soal pilihan ganda yang terdiri dari 30 soal yang telah diuji validitas dan reliabilitasnya.
1. Hasil Nilai Post TestMata Kuliah Pengaturan Motor pada Kelas yang

Menggunakan Media Pembelajaran

Berbasis Video.

Berdasarkan hasil data yang

diperoleh dari 30 siswa, didapat

nilai tertinggi yaitu 96,66 dan

nilai terendah yaitu 70 dengan

rata-rata yaitu 83 (A-). Diperoleh

median82,41, modus 82 , varian

42,33 dan simpangan baku

sebesar 6,5.

2. Hasil Nilai Post TestMata

Kuliah Pengaturan Motor pada

Kelas yang Tidak Menggunakan

Media Pembelajaran Berbasis

Video.

Berdasarkan hasil data yang diperoleh dari 30 siswa, didapat nilai tertinggi yaitu 90 dan nilai terendah yaitu 70 dengan rata-rata yaitu 80,56 (B+). Diperoleh median sebesar 80, modus 79,1, varian 37,27 dan simpangan baku 6,1. Dengan menggunakan perhitungan statistika didapatkan kelas interval yaitu 4 .

4. Perbedaan Hasil Varian dan Simpangan Baku antara Dua Kelas

Varian yang didapat kelas eksperimen 42,33 dan simpang bakunya 6,5. Varian yang didapat kelas kontrol 37,27 dan simpang bakunya 6,1 . Dari perolehan data tersebut bahwa varian dan simpang baku kelas eksperimen lebih tinggi daripada varian dan simpang baku kelas kontrol.Jadi, dapat disimpulkan bahwa data hasil nilai post test kelas eksperimen lebih beragam atau bervariasi daripada kelas kontrol.

\section{Pembahasan}

Faktor pendukung dalam penelitian ini adalah komponen-komponen pengaturan motor sudah tersedia di laboraturium dan mahasiswa antusias dalam menggunakan media pembelajaran berbasis video mata kuliah pengaturan motor. Faktor penghambat dalam penelitian ini yaitu saat merangkai banyak bahan dan tools yang tidak ada seperti tang potong, tang skun, dan kabel. Saat pengambilan gambar atau shooting keadaan luar ruangan terlalu berisik, sehingga menunggu sampai tidak terlalu berisik. 
Kelebihan media pembelajaran berbasis video mata kuliah pengaturan motor adalah dapat dilihat mmelalui komputer, laptop atau DVD. Selain itu terdapat simulasi yang dapat memudahkan mahasiswa dalam memahami cara kerja rangkaian. Kelemahan media pembelajaran berbasis video mata kuliah pengaturan motor adalah pada saat proses pengambilan gambar dilakukan di ruangan yang tidak kedap suara dan tidak menggunakan microphoneexternal, sehingga suara dari luar ruangan ikut terekam. Antara suara yang di dubbing dan yang tidak di dubbing tidak seimbang.

\section{KESIMPULAN \\ Kesimpulan}

Berdasarkan hasil data dan pembuatan media pembelajaran berbasis video mata kuliah pengaturan motor dapat disimpulkan bahwa:

1. Media pembelajaran berbasis video mata kuliah pengaturan motor dibuat melalui 3 tahapan yaitu tahap perencanaan, tahap produksi dan tahap penyelesaian akhir.

2. Hasil Uji Kelayakan media pembelajaran berbasis video mata kuliah pengaturan motor dengan perolehan skor dari ahli materi sebesar 94,23\% (sangat baik), skor dari ahli media sebesar 91,66\% (sangat baik) dan skor dari responden mahasiswa sebesar $86,13 \%$ (sangat baik). Hasil data tersebut melebihi $80 \%$ (sangat baik) sehingga media pembelajaran berbasis video mata kuliah pengaturan motor dinyatakan layak.

3. Data yang diperoleh dari rata-rata hasil nilai post test mata kuliah pengaturan motor yang menggunakan media pembelajaran berbasis video adalah 83 (A-) dan yang tidak menggunakan media pembelajaran berbasis video adalah 80,56 (B+). Dari data tersebut menunjukkan bahwa rata-rata hasil nilai post test mata kuliah pengaturan motor yang menggunakan media pembelajaran berbasis video lebih tinggi dibandingkan dengan yang tidak menggunakan media pembelajaran berbasis video. Varian yang didapat kelas eksperimen (yang menggunakan media berbasis video) sebesar 42,33 dan simpang bakunya 6,5. Varian yang didapat kelas kontrol (yang tidak menggunakan media berbasis video) sebesar 37,27 dan simpang bakunya 6,1. Dari perolehan data tersebut bahwa varian dan simpang baku kelas eksperimen lebih tinggi daripada varian dan simpang baku kelas kontrol. Jadi, dapat disimpulkan bahwa data hasil nilai post test kelas eksperimen lebih beragam atau bervariasi daripada kelas kontrol.

\section{Saran}

Dari penelitian yang penulis lakukan maka disarankan agar:

1. Media pembelajaran berbasis video mata kuliah pengaturan motor dipakai sebagai media pembelajaran guna meningkatkan hasil belajar.

2. Menggunakan alat-alat pendukung seperti microphone external dan lampu tembak agar terlihat baik di suara maupun pencahayaannya.

3. Jika menggunakan suara dubbing sebaiknya dilakukan penjernihan suara terlebuh dahulu agar suara yang dihasilkan bagus dan sama.

4. Perlu adanya pelatihan-pelatihan pembuatan media pembelajaran yang interaktif untuk dosen agar terdapat variasi dalam proses pembelajaran.

\section{DAFTAR PUSTAKA}

Arikunto, Suharsimi. DasarDasarEvaluasiPendidikan. (Jakarta:Bumi Aksara, 2003)

Arikunto, Suharsimi.Dasar-Dasar Evaluasi Pendidikan.(Jakarta: Bumi Aksara, 2009)

Arindya, Radita. Penggunaan dan Pengaturan Motor Listrik. (Yogyakarta: Graha Ilmu, 2013)

Astuti, Reni. Studi Perbandingan Kemampuan Komunikasi Matematik dan Kemandirian Belajar Siswa pada Kelompok Siswa yang Belajar Reciprocal Teaching dengan Pendekatan Metakognitif dan Kelompok Siswa yang Belajar dengan Pembelajaran Biasa. (Bandung: UPI, 2009 ) 
Arsyad, Azhar. Media Pembelajaran. (Jakarta:

PT. Raja Grafindo Persada, . 2011)

Kustandi, Cecep dan Bambang Sutjipto. Media Pembelajaran. (Bogor: Ghalia Indonesia, 2011)

Mulyatiningsih, Endang. Metode Penelitian Terapan Bidang pendidikan. (Bandung: Alfabeta, 2014)

Oemar, Hamalik.Media Pembelajaran.

(Bandung: PT. Citra Aditya Bakti, 1994)
Porter, Bobby De dkk. Quantum Teaching Mempraktikan Quantum Learning di Kelas. (Bandung: Mizan, 2000)

Sadiman, Arief S. dkk. Media Pendidikan. Jakarta: Rajawali Pers.

Sugiyono. Metode Penelitian Kuantitatif Kualitatif dan $R \& D$. (Bandung : Alfabeta, 2009)

Suryabarata. Metode Penelitian. (Jakarta: PT. Grafindo Persada, 2005) 